\title{
On the electrical perforation of glass
}

\section{Prof. A. Von Waltenhofen}

To cite this article: Prof. A. Von Waltenhofen (1879) On the electrical perforation of glass, Philosophical Magazine Series 5, 7:44, 374-375, DOI: 10.1080/14786447908639626

To link to this article: http://dx.doi.org/10.1080/14786447908639626

$$
\text { 曲 Published online: } 13 \text { May } 2009 .
$$

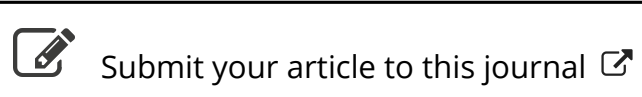

\footnotetext{
Џll Article views: 2
}

Q View related articles $\sqsubset$ 
another whenever it ceases. In short, this is a completely automatic candle requiring only a very simple support; the lighting, the fixing at the desired distance, and the maintenance of the arc at the two points result spontaneously from the electromagnetic forces, which take upon themselves the whole of the work. It is moreover evident that these forces are proportional to the square of the intensity of the current, and can always be rendered sufficient; it is only a question of construction. M. Fernet proposed to place the carbons one in the prolongation of the other, and to take advantage of their repulsion to separate them. This repulsion was but feeble; in the solution proposed by me the action is more energetic and becomes efficient.

When the action of the rectangle is sufficient, the are, spread out and driven beyond the points, has the appearance of a gas-flame; its length is increased. From this results a greater expenditure of electromotive force; and the amount of light is not increased proportionately; for it is known that, if the arc attains a very high temperature, it does not possess a brightness comparable with that of the carbon points. But on remarking that the are was projected outside, I conceived the idea of receiving it upon lime, magnesia, or zircon, like the oxyhydrogen-flame in the Drummond lamp. The arc is crushed by this obstacle, keeps a constant length, and, far from consuming more electromotive force, it saves a notable portion, because it springs in a highly heated and more conductive space. On the other hand, the light, instead of disappearing skywards, where it is useless, is reflected toward the ground; this will permit the electric lamp to be placed at a great elevation, out of the usual direction of looking. Besides, the light is altogether changed : it is no longer violet, but white; it eren appears greenish yellow by contrast and by the augmented intensity of the green lines of the lime; and, finally (the most raluable result of all), it is at least three times as intense as without the cap of lime. In truth, that cap must not rest upon the points ; for these will fuse and penetrate the lime, and the arc will find its path inwards and shine no more. This defect can easily be remedied.

The fusion of the lime proves that the arc thus projected by a magnetic effect is capable of considerably heating all bodies; it is a real blowpipe-probably the most powerful of all. I recommend it to chemists and physicists. I shall myself have to entertain the Academy with the powerful effects that can be obtained from it.-Comptes Renclus de l'Aoctémie des Sciences, March 17, 1879, t. Ixxxviii. pp. 541-544.

\section{ON THE ELECTRICAL PERFORATION OF GLASS.}

BY PROF. A. VON WALTENHOFEN.

In connexion with his experiment described in 1866 , and with a treatise referring to it, by E. Mach and S. Doubrava, just published, the author describes the following additional experiments:-

A thin glass plate having upon it ever so small a drop of stearine, introduced into the path of the spark of an electrical 
machine, is perforated at that place, and more readily if the side on which the drop lies be turned towards the positive electrode.

A glass plate with bifilar suspension between the electrodes of a Holtz machine is driven by the discharge toward the negative clretrode, and, indeed, with more force if the side turned to the positive electrode is partially coated with stearine.

Fixed points for an explanation of these facts are found by the author in the assumption, once previously enunciated, and on that occasion also advocated by $G$. Wiedemann, that the air molecules in the sparls path are affected, in their certainly very energetic motions, with a velocity-component directed from the positive to the negative electrode, such as was originally attributed by Plücker, and after him by Reitlinger, to the positive electricity itself.Kaiserliche Akademie der Wissensehaften in Wien, math.nature". Classe, March 6, 1879.

\section{ON THE PRESSURES EXERTED BY GALVANIC DEPOSITS,}

\section{BY M. BOUTY.}

If we take a thermometer with a cylindrical reservoir, render it couductive by coating it with gold leaf or thinly silvering it, and employ it as the negative electrode in the decomposition of a copper-salt (for instance), the metallic deposit exerts a considerable pressure upon the reservoir ; for the mercury rises in the stem the more as the deposit is thicker. And to explain this ascent one can neither invoke a local rise of temperature, which is insignificantnor an electrical action properly so called; for the thermometrical excess has no direct relation with the intensity of the current, and persists integrally after the suppression of the latter. It depends exclusively on the more or less perfectly metallic quantity of the deposit, and will probably be capable of supplying the indirect measure of it. Very crystalline or coarsely granular deposits exert but a trifling compression. When we dissolve the metal with an acid the thermometer becomes normal again.

Professor Mills*, who discovered before I did, and without my being aware of it when I commenced this investigation, the fact of the contraction of thermometers, announced that copper, silver, iron, and nickel contract, and that cadmium and zinc dilate the reservoirs upon which they are applied. I have found that all metals, including zinc, always act only by pressure; but the pressure is not necessarily normal, or the same at all points, and camnot serve directly as a measure for the phenomenon. It is the result of a change of volume undergone by the metal in being deposited. I shall confine myself to the establishment of this point, reserving for an ulterior Note all the peculiarities I have observed.

Let us imagine that a cylinder $M$ of external radius $\mathbf{R}$ and indefinite length becomes corered with a regular solid coat of which the external radius is $R^{\prime}$. It undergoes a shrinkage, the amount of which would be a fraction $"$ of its internal volume if the cylinder M offered no resistance; but as it does resist, a normal pressure * Proceedings of the Royal Society, vol, xxvi. p. 504. 